\title{
Preparation of Low Cost Solid State Silver Sulfide Based Bromide Selective Electrodes
}

\author{
Amar Prasad Yadav* \\ Central Department of Chemistry, Tribhuvan University, Kirtipur, Kathmandu, Nepal \\ e-mail:amar2y@yahoo.com
}

\begin{abstract}
Preparation and performance of a cost effective silver sulfide based bromide selective membrane is described. A solid contact between membrane and body of the electrode was examined as an ion-selective electrode by determining $\mathrm{S}^{2-}$ and $\mathrm{Br}$ ions by direct potentiometry. A linear response to bromide ion from $2 \times 10^{-5}$ to $10^{-1} \mathrm{M}$ with a slope of $57.3 \mathrm{mV}$ per decade $\left[\mathrm{Br}^{-}\right]$is observed. The membrane has a very short response. It gives excellent results as an indicator electrode for potentiometric titration.
\end{abstract}

Keywords: Ion-selective electrodes, bromide ion sensor, potentiometry, selectivity

\section{Introduction}

A solid state ion-selective electrode (ISE) provides solid state internal contact between a metal conductor and the ion-selective membrane. This contact gives the solid state ion-selective electrode several advantages over ion-selective electrode with liquid fillings. ${ }^{1}$ Silver halide based ion-selective electrodes have several desirable properties for the potentiometric determination of halides as well as silver ions. Three types of halide ion-selective electrodes are in use. The first type is a halide precipitate immobilized on silicon rubber $^{2}$ and the second one uses single crystals ${ }^{3}$. Though these membranes have shown good response characteristics to silver and halide ions, an unwelcome property of these electrodes is their sensitivity to light ${ }^{3}$. The third type, which is widely used, consists of a membrane composed of a mixture of silver halide and silver sulfide. Silver sulfide being far less soluble than any of silver halides and having low resistivity and mixed electronic and ionic conductivity is incorporated with silver halide to attain decreased light sensitivity, increased detection limit and greater mechanical stability of such membranes.

There is no dearth of literature on the ISE but technical details on the fabrication of ISE are not available and often patented ${ }^{4,5}$. At the same time, it is not always affordable to buy commercial ion-selective electrodes for the purpose where many people may use it, e.g. for laboratory experiment involving many students. Therefore, the purpose of this study was to prepare an inexpensive and easy to construct all solid state bromide ion selective electrodes

\section{"Corresponding author}


from a mixture of silver bromide and silver sulfide by optimizing different preparation parameters and to characterize and compare its performance with the commercial electrodes.

\section{Experimental Methods}

AR grade silver nitrate, potassium bromide, potassium iodate and ascorbic acid and laboratory reagent grade hydrochloric acid, sodium sulfide, sodium nitrate and sodium hydroxide were obtained from Ranbaxy and used as received without any purification. Aqueous solutions were prepared in distilled water. A stock solution of sodium sulfide was standardized with potassium iodate solution by standard method ${ }^{6}$ and it was appropriately diluted for use. Similarly, a stock solution of silver nitrate was prepared and it was standardized by sodium chloride solution potentiometrically.

Bromide selective membrane was prepared from the co-precipitation of silver sulfide and silver bromide. To an aqueous solution containing equal molar concentrations of potassium bromide and sodium sulfide an excess of silver nitrate solution was added, a co-precipitate of silver sulfide and silver bromide was obtained. The precipitate thus obtained was filtered off, thoroughly washed with distilled water and finally with acetone. It was dried at $110^{\circ} \mathrm{C}$ for an hour and pulverized in a mortar. A membrane of about $1.5 \mathrm{~mm}$ thickness was prepared by pressing dried powder of precipitates at a pressure of 14 tones for 15 minutes under vacuum using a $\mathrm{KBr}$ die with a $12 \mathrm{~mm}$ diameter plunge. Subsequently it was cured at $200^{\circ} \mathrm{C}$ for half an hour.

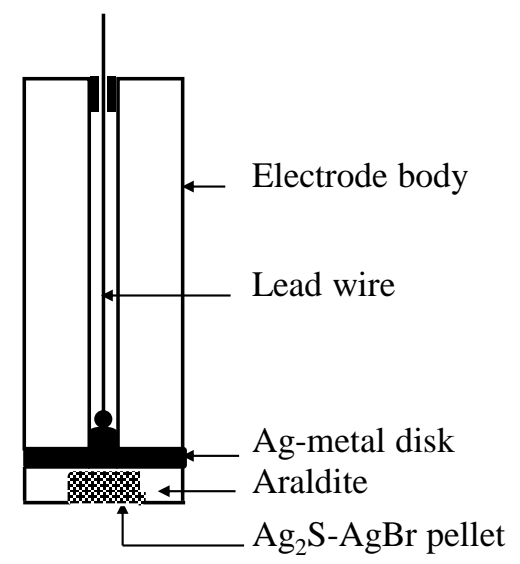

Figure 1: Schematic of electrode body

The electrode body consisted of a PTFE rod with a silver metal disk and a coaxial cable for electrical contact as shown in Fig. 1. The contact between membrane and silver disk was attained by a very simple technique, which involved the deposition of silver on one side of membrane by electroplating in ammoniacal silver nitrate bath at current density of $1 \mathrm{~mA} / \mathrm{cm}^{2}$ for 30 minutes. The membrane was finally mounted in the PTFE rod with Araldite and polished on an emery paper and finally in a Bolton cloth to mirror finishes before starting measurements.

A WPA CD 300 model digital $\mathrm{pH}$ meter was used for all potentiometric measurements at $25^{\circ} \mathrm{C}$. An Elico commercial silver ion-selective electrode was also used to compare the results 
with respect to silver ion. All the potentials were measured against saturated calomel electrode. The experimental cell can be represented as:

$$
\mathrm{Hg} / \mathrm{Hg}_{2} \mathrm{Cl}_{2} \text { (Sat)// Test solution }(\mu=\text { constant }) / \text { ISE }
$$

The response of the electrode for $\mathrm{Br}^{-}$and $\mathrm{Ag}^{+}$ions was measured by standard addition methods (at constant $\mathrm{pH}$ ), keeping the ionic strength constant, $\mu=0.1 \mathrm{M}$ by using appropriate amount of sodium nitrate as background electrolyte. On the other hand, the response of the electrode for $\mathrm{S}^{2-}$ ion concentrations was obtained by serial dilution of sodium sulfide solution at constant ionic strength and at $\mathrm{pH} 11.7$ to 12.0 by adding appropriate volume of $1 \mathrm{M} \mathrm{NaOH}$. The test solution also contained one $\mathrm{mg} / \mathrm{ml}$ ascorbic acid to prevent aerial oxidation of sulfide to sulfate. $^{7}$

Potentiometric titration of sodium sulfide by hydrochloric acid was followed by both glass electrode and laboratory made electrode in a well-closed vessel. In addition, titration of potassium bromide by silver nitrate was carried out. Dynamic response of the electrodes were obtained after rapid concentration of the test solution by the addition of more concentrated solution of appropriate ions and noting the emf at the interval of 30 seconds till equilibrium potential was obtained. Selectivity of electrode for other anions was determined by mixed solution method following the standard procedure ${ }^{7}$. Throughout the measurement the solution was stirred with a PTFE-coated magnetic bar. The stirring speed and electrode distance were both kept constant.

\section{Results and Discussion}

Response to $\mathrm{Br}^{-}$and $\mathrm{S}^{2-}$ ions

The response of the $\mathrm{Ag}_{2} \mathrm{~S}-\mathrm{AgBr}$ membrane to $\mathrm{Br}^{-}$ion is shown in Fig. 2. The points are the experimental results and the line is the line of best fit. The maximum response time of the cell potential was $1 \mathrm{~min}$, even at low concentration. The electrode reached a steady state potential within the time of the experiments. In all the experiment, the potential drifts were parallel and relatively small. The membrane showed linear response to as low as $2 \times 10^{-5} \mathrm{M} \mathrm{Br}^{-}$ion concentration with the slope $57.3 \mathrm{mV} / \mathrm{pBr}^{-}$. This experimental slope, though lower than theoretical value, agreed well with the reported values. Rechnitz et al. ${ }^{8}$ has reported a linear range down to $7 \times 10^{-5} \mathrm{M} \mathrm{Br}^{-}$with a slope of about $52 \mathrm{mV} / \mathrm{pBr}^{-}$.

In the linear region, the emf of the cell response follows the following equation

$$
\mathrm{E}=-0.175-0.05729 \log \left[\mathrm{Br}^{-}\right]
$$

Here the standard potential for the reaction ; $\operatorname{AgBr}(\mathrm{s})+\mathrm{e}=\mathrm{Ag}(\mathrm{s})+\mathrm{Br}^{-}$was found by extrapolating the appropriate potential line to potential axis at zero concentration. If the junction potential is ignored and after a correction of $244 \mathrm{mV}$ for the potential of calomel reference electrode at $25^{\circ} \mathrm{C}$, a value of $\mathrm{E}^{\circ}=0.069 \mathrm{~V}$ vs $\mathrm{SHE}$ is obtained which is very close to the theoretical value of $0.071 \mathrm{~V}$.

When the membrane was soaked for long time $(24 \mathrm{~h})$ in $10^{-2} \mathrm{M} \mathrm{KBr}$ solution, the surface of bromide selective membrane was slightly tanned and the electrode lost its nernstian behavior but showed satisfactory potential response after it was re-polished. The tanning of the 
membrane surface has been described to occur due to the formation of soluble complex $\mathrm{K}\left[\mathrm{AgBr}_{2}\right]^{2}$. Table 1 shows the results of co-relation analysis. The selectivity of a commercial sulfide ion-selective electrode has been reported to be in the same range of sulfide ion concentration as obtained in this study; however better slope of $-30 \mathrm{mV}$ is reported. ${ }^{9}$

Response of the bromide selective membrane to sulfide ion was checked and a typical result is shown in Fig. 3. The linearity range is extended down to $10^{-6} \mathrm{M} \mathrm{S}^{2-}$ with the slope of -33 $\mathrm{mV} / \mathrm{pS}^{2-}$, slightly higher than nernstian value for two-electron transfer reaction. The influence of ionic strength on the intercept of the potential line is obvious as the ion-selective membrane

Table 1: Different constants obtained by co-relation analysis

\begin{tabular}{lcccc}
\hline Electrodes & $\begin{array}{c}\text { Determinant } \\
\text { ion }\end{array}$ & Slope (mV) & $\begin{array}{c}\text { Intercept } \\
(\mathrm{mV})\end{array}$ & $\begin{array}{c}\text { Co-efficient of } \\
\text { determinant }\end{array}$ \\
\hline $\mathrm{Ag}_{2} \mathrm{~S}-\mathrm{AgBr}$ & $\mathrm{Br}^{-}$ & 57.3 & -175.0 & 0.9803 \\
$\mathrm{Ag}_{2} \mathrm{~S}-\mathrm{AgBr}$ & $\mathrm{Ag}^{+}$ & 59.9 & 559.9 & 0.9975 \\
$\mathrm{Ag}_{2} \mathrm{~S}-\mathrm{AgBr}$ & $\mathrm{S}^{2-}$ & -33 & -912.0 & 0.9961 \\
Elico brand & $\mathrm{Ag}^{+}$ & 59.1 & 646.3 & 0.9974 \\
Orion- 94-16 & $\mathrm{S}^{2-}$ & -30 & -911.0 & [Ref 10] \\
\hline
\end{tabular}

sense the activity of determinant ion rather than concentration. The potential of the cell at $0.1 \mathrm{M}$ ionic strength is given by equation (3)

$$
\mathrm{E}=-0.912-0.033 \log \left[\mathrm{S}^{2-}\right]
$$

Both the membranes were found to response very well to silver ion concentration from $10^{-1}$ to $5 \times 10^{-6}$ with the slope of $59.9 \mathrm{mV} / \mathrm{pAg}^{-1}$. The response to silver ion was compared with commercial Elico brand silver ISE and the result is presented in Table 1. When the membrane was immersed in a low concentration of appropriate ion and the concentration was increased by five times, the potential took a stable value within $1 \mathrm{~min}( \pm 1 \mathrm{mV})$. A typical curve obtained for $\mathrm{Br}^{-}$is shown in Fig. 4, showing smooth and identical shape. This means the response time of the electrode is independent of the initial concentration of chloride ion over the studied range. However, the response time was found to be dependent on the efficiency of the solution mixing and cleanliness of the surface. From the above discussion, it is obvious that the present laboratory made bromide ISE is well suited for direct potentiometric determination of $\mathrm{Br}^{-}$ions.

\section{Potentiometric titration}

One of the most widely used filed of ion-selective electrode is in the potentiometric titration. In combination with the calomel reference electrode at fixed ionic strength of $0.1 \mathrm{M}$, these two sets of titration were carried out: (a) $\mathrm{Na}_{2} \mathrm{~S}$ with $0.1 \mathrm{M} \mathrm{HCl}$ and (b) $\mathrm{AgNO}_{3}$ with $0.1 \mathrm{M} \mathrm{KBr}$. A typical potentiometric curve obtained for the titration of $50 \mathrm{ml}$ of $\mathrm{Na}_{2} \mathrm{~S}$ with $0.1 \mathrm{M} \mathrm{HCl}$ (in Fig. $5)$. The titration was carried out in well-covered container with ionic strength set at $0.1 \mathrm{M}$ with appropriate volume of $\mathrm{NaOH}, \mathrm{pH} 12.1$ and $1 \mathrm{mg} / \mathrm{ml}$ ascorbic acid. Two end points were obtained with the second end point at slightly higher volume of $\mathrm{HCl}$ in both the cases. It can be 
concluded that for such a system instead of a glass electrode, ion-selective membrane can be used with the same accuracy. Figure 6 shows the potemtiometric titration curve. The inflexion in the titration curves near the equivalence point shows that the ISE is well suited as indicator electrodes.

\section{Selectivity co-efficient determination}

Selectivity of bromide membrane was checked in iodide and chloride ions by mixed solution method. The activity of interfering ion was kept constant while increasing the concentration of determinant ion. Following the standard method ${ }^{7}$, the selectivity co-efficient was calculated and is tabulated in Table 2. The iodide ion was found to interfere in the determination of $\mathrm{Br}^{-}$ion while chloride ion has no interfering effect on the entire range of concentration studied. This is well explained by the solubility product of AgI, which is much less than that of $\mathrm{AgBr}$.

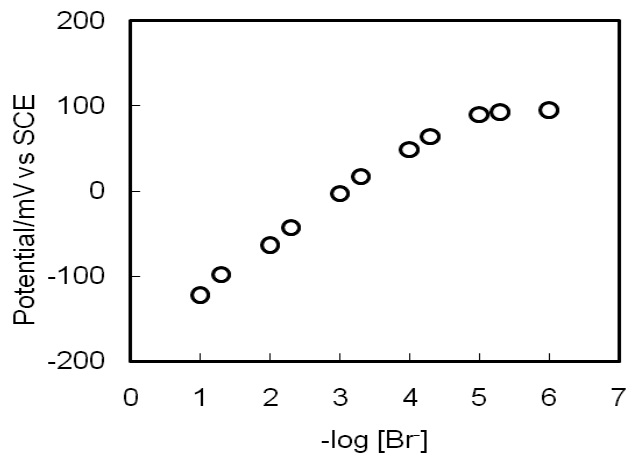

Figure 2: Response to $\mathrm{Br}$ - ion with a bromide selective membrane electrode

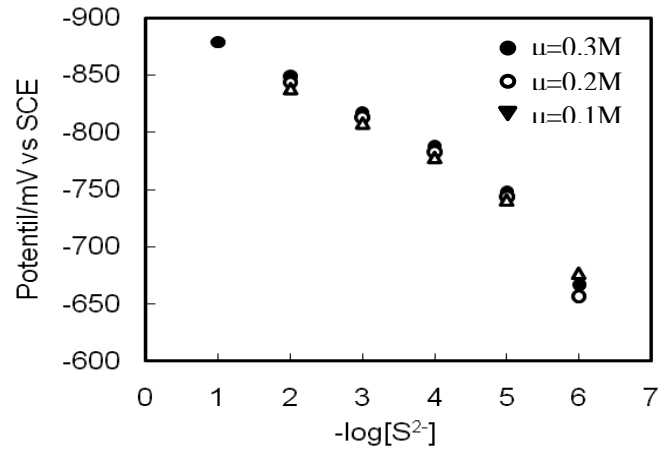

Figure 3: Response of the electrode to $S^{2-}$ ions with a bromide selective membrane electrode at different ionic strength

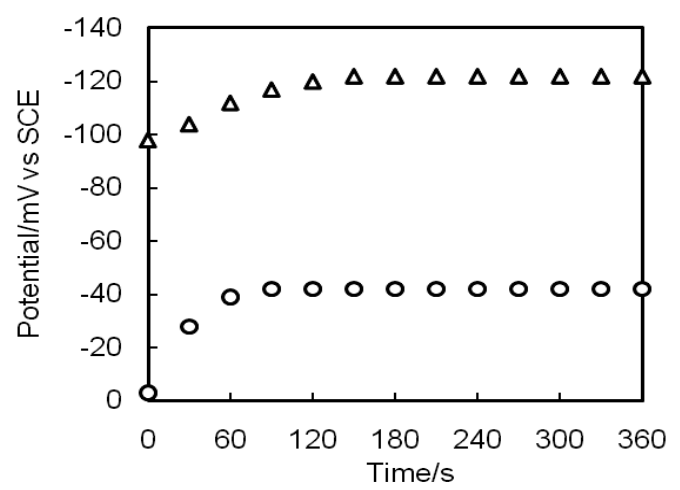

Figure 4: Dynamic response of $\mathrm{Ag} 2 \mathrm{~S}-\mathrm{AgBr}$ membrane to $\mathrm{Br}{ }^{-}$ion concentration at 0.1 M ionic strength 


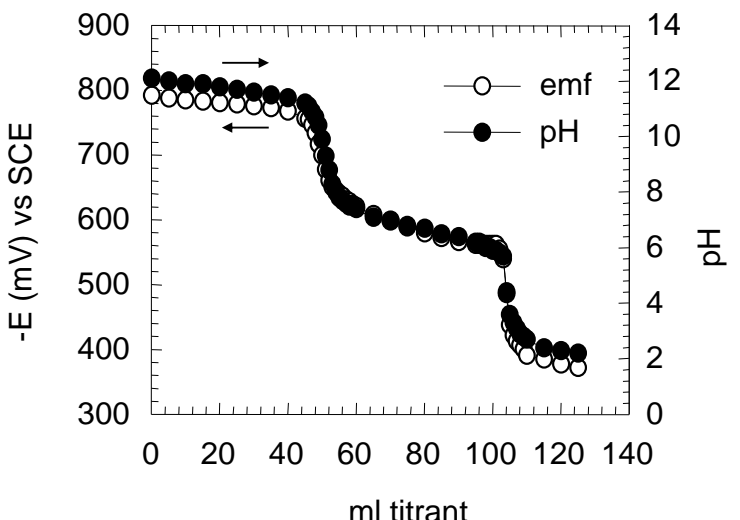

Figure 5: Titration of $50 \mathrm{ml}$ of $0.1 \mathrm{M} \mathrm{Na2S}$ with $0.1 \mathrm{M} \mathrm{HCl}$ at $0.1 \mathrm{M}$ ionic strength

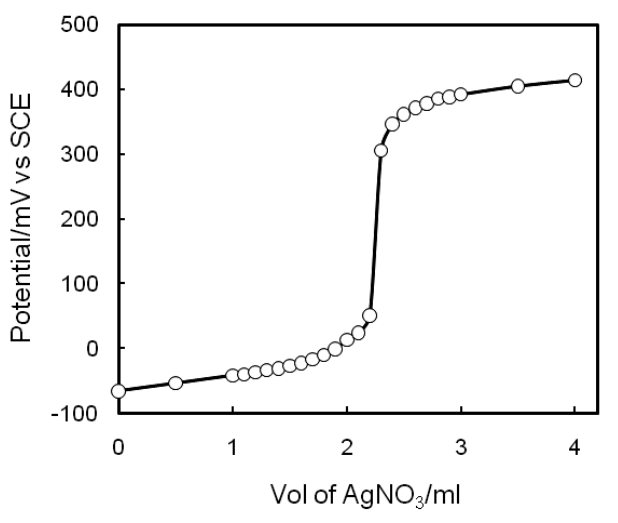

Figure 6: Potentiometric titration of $20 \mathrm{ml}$ of $\mathrm{KBr}$ with $0.1 \mathrm{MAgNO}$ at $0.1 \mathrm{M}$ ionic strength

Table 2: Different constants obtained by co-relation analysis

\begin{tabular}{c|l|l}
\hline Electrode & \multicolumn{1}{|c}{ Interfering Ion } & Selectivity Coefficient \\
\hline $\mathrm{Ag}_{2} \mathrm{~S}-\mathrm{AgBr}$ & {$\left[\mathrm{I}^{-}\right] 10^{-4} \mathrm{M}$} & 4 \\
$\mathrm{Ag}_{2} \mathrm{~S}-\mathrm{AgBr}$ & {$\left[\mathrm{Cl}^{-}\right] 10^{-2} \mathrm{M}$} & $8 \times 10^{-2}$ \\
\hline
\end{tabular}

\section{Conclusions}

An easy to fabricate and inexpensive bromide selective membrane was prepared and characterized. The response was found to be comparable with commercial electrode and analysis by direct potentiometry and potentiometric titration was sufficiently precise and reproducible. A linear response to bromide ion from $2 \times 10^{-5}$ to $10^{-1} \mathrm{M}$ with a slope of $57.3 \mathrm{mV}$ per decade [Br-] and to sulfide ion from $1 \times 10-6$ to $10-1 \mathrm{M}$ with slope of $33 \mathrm{mV}$ per decae $\left[\mathrm{S}^{2-}\right]$ were observed. The long time stability and applicability of the membrane for more than one ion need further investigations.

\section{References}

1. B. P. Nikolski and E. A. Materova, Ion-Select. Electrode Rev., 1985, 7, 3

2. E. Pungor and K.Toth, Analyst, 1970, 95, 625

3. W. A. B. Donners and D. A. Wooys, J. Eletcroanal. Chem., 1974, 52, 271

4. Indian patent, BARC IN, 1987, 160, 6112

5. A. F. Zhukov, USSR patent, 1988, 1364 966; Chem. Abstr., 1986, 108, 197506p

6. G. H. Jeffery, J. Bassett, J. Mendham and R. C. Denney, "Vogel's Text Book of Quantitative Chemical Analysis", 1989, Longman Group UK Limited, 400 
7. P. L. Bailey, "Analysis with Ion-Selective Electrodes", 1980, Heyden International Topics in Science, London, 113

8. G. A. Rechnitz, M. R. Kresz and S. B. Zamochnick, Anal. Chem., 1966, 38, 1787

9. T. M. Hseu and G. A. Rechnitz, Anal. Chem., 1968, 40, 1059. 